\title{
Public health impact and economic evaluation of vitamin D-fortified dairy products for fracture prevention in France
}

\author{
M. Hiligsmann ${ }^{1}$ • N. Burlet $^{2}$ • P. Fardellone ${ }^{3} \cdot$ N. Al-Daghri ${ }^{4} \cdot$ J.-Y. Reginster ${ }^{2}$
}

Received: 23 June 2016 / Accepted: 22 September 2016 /Published online: 18 October 2016

(C) The Author(s) 2016. This article is published with open access at Springerlink.com

\begin{abstract}
Summary The recommended intake of vitamin D-fortified dairy products can substantially decrease the burden of osteoporotic fractures and seems an economically beneficial strategy in the general French population aged over 60 years.

Introduction This study aims to assess the public health and economic impact of vitamin D-fortified dairy products in the general French population aged over 60 years.

Methods We estimated the lifetime health impacts expressed in number of fractures prevented, life years gained, and quality-adjusted life years (QALY) gained of the recommended intake of dairy products in the general French population over 60 years for 1 year (2015). A validated microsimulation model was used to simulate three age cohorts for both women and men $(60-69,70-79$, and $>80$ years). The incremental cost per QALY gained of vitamin D-fortified dairy products compared to the absence of appropriate intake was estimated in different populations, assuming the cost of two dairy products per day in base case.
\end{abstract}

M. Hiligsmann

m.hiligsmann@maastrichtuniversity.nl

1 Department of Health Services Research, School for Public Health and Primary Care (CAPHRI), Maastricht University, P.O. Box 616, 6200 MD Maastricht, The Netherlands

2 Department of Public Health, Epidemiology and Health Economics, University of Liège, Liège, Belgium

3 Department of Rheumatology, Centre Hospitalier Universitaire d'Amiens, INSERM U1088, Amiens, France

4 Prince Mutaib Chair for Biomarkers of Osteoporosis, Biochemistry Department, College of Science, King Saud University, Riyadh 11451, Saudi Arabia
Results The total lifetime number of fractures decreased by 64,932 for the recommended intake of dairy products in the general population over 60 years, of which 46,472 and 18,460 occurred in women and men, respectively. In particular, 15,087 and 4413 hip fractures could be prevented in women and men. Vitamin D-fortified dairy products also resulted in 32,569 QALYs and 29,169 life years gained. The cost per QALY gained of appropriate dairy intake was estimated at $€ 58,244$ and fall below a threshold of $€ 30,000$ per QALY gained in women over 70 years and in men over 80 years. Conclusion Vitamin D-fortified dairy products have the potential to substantially reduce the burden of osteoporotic fractures in France and seem an economically beneficial strategy, especially in the general population aged above 70 years.

Keywords Cost-effectiveness - Dairy products $\cdot$ Fractures · France $\cdot$ Public health

\section{Introduction}

Osteoporotic fractures represent a major public health problem that leads to increased morbidity, mortality, and health care costs [1]. In France, it was estimated that 50,215 and 15,482 hip fractures occurred in the year 2013 in women and men, respectively [2]. In another report prepared in collaboration between the International Osteoporosis Foundation (IOF) and the European Federation of Pharmaceutical Industry Associations (EFPIA), the economic burden of incident and previous fragility fractures was estimated at $€ 4853$ million in France and fractures accounted for 139,400 qualityadjusted life years (QALYs) lost in 2010 [1].

Calcium and vitamin D are crucial for bone health and fracture prevention. A European consensus group recommends adequate vitamin D intake of $800 \mathrm{IU} /$ day and calcium 
intake of $1000 \mathrm{mg}$ per day [3]. Several studies reported a high prevalence of vitamin D insufficiency and low dietary calcium in many elderly men and women $[4,5]$. In France, only $20 \%$ of women consumed $\geq 1000 \mathrm{mg}$ of calcium per day [6] and the prevalence of vitamin D inadequacy is $>85 \%$ in women with osteoporosis or osteopenia aged over 50 years as well as in elderly subjects above 80 years $[5,7]$. Several studies have reported that the current intake of calcium and vitamin D is far from optimal in France [6, 8-10]. By example, one large scale study estimated that, respectively, 73.9 and $86.5 \%$ of elderly women have low dietary intakes of vitamin $\mathrm{D}$ and low dietary calcium intakes [8]. It is therefore important to adequately supplement elderly patients with calcium and vitamin D [3, 11]. The use of dietary sources of calcium has been recommended as the preferred option by the European guidance for the diagnosis and management of osteoporosis [12]. The French National Nutrition and Health Program recommends the consumption of three dairy product servings/day for adults ( 3 to 4 for over 55 -year-olds) but only $29 \%$ of French adults meet this recommendation [13].

Assessing the public health and economic impact of the recommended intake of dairy products and vitamin D would be important to help policy makers in evaluating and making decisions about preventive programs, especially in the context of limited health care resources. To date, relatively few studies have assessed the public health and economic impact of vitamin D-fortified dairy products given to the general elderly population [14-17]. These studies suggest the public health and economic value of fortified dairy products. To our knowledge, no study has been conducted to assess the public health and economic impact of vitamin D-fortified dairy products for fracture prevention in France.

This study therefore aimed to estimate the public health and economic impact of dairy products supplemented with vitamin D in the general population aged over 60 years in France. Specifically, we estimated the impact of the recommended intake of fortified dairy products on the number of fractures prevented, on life years gained, on gained, and evaluated the cost-effectiveness of fortified dairy products compared with the absence of appropriate intake in terms of cost per QALY gained.

\section{Methods}

We used a previously validated Markov microsimulation model [18] to estimate the public health and economic impact of the recommended intake of vitamin D-fortified dairy products in France compared to the absence of appropriate intake. The model simulates over lifetime the number of fractures (hip, clinical vertebral, wrist, other and all), life years, QALY, and total health care costs. The more recent version of the model with a 6-month time horizon was used in this study [17, 19] and was adjusted to the French setting. In a Markov model, patients transit between different health states (no fracture, fractures, post fracture, and death) according to transition probabilities. Description of the model can be found in previous publications $(9,10)$.

Analyses were conducted in the general population in France aged over 60 years, including women and men. In both genders, three age cohorts (60-69 years, 70-79 years, $80+$ ) were used to estimate outcomes using the software TreeAge Pro 2011 (TreeAge Pro Inc., Williamston, MA). For each cohort, we simulated 1,000,000 microsimulations. The base year of the analysis was 2015 . We therefore estimated the impact of vitamin D-fortified dairy products to all individuals for 1 year (2015 base case) and estimated the lifetime effect of this intervention. Based on the distribution of the population in each cohort that was obtained from the National Institute of Statistics and Economic Studies (INSEE) [20] (see Table 1), we then calculated using an Excel sheet, the total costs, and outcomes in the general French population aged above 60 years. Projections for the years 2025 and 2050 were also done using populations projections from INSEE [21] to evaluate the effects of demographic changes on the benefits of the strategy.

Incidence of hip fractures in the general population was derived from the recent study of Briot et al. [2] using data from the year 2013 (see Table 2). As no data for the incidence of other osteoporotic fractures (i.e., clinical vertebral, wrist, and other fractures) are available in France, we applied the age-specific ratio incidence from other countries in line with previous publications [1]. In addition, the model assumed an increased risk of fracture for individuals who had a prior fracture at the same location [18]. Mortality data for the general population were derived from INSEE for the years 2011-2013 [22]. According to data from a meta-analysis [23], hip fractures increased female (male) death probabilities by 4.53 (5.75) in the first 6 months following the fracture, by 1.75 (2.31) in the period 6-12 months, and by 1.78 (1.69) in subsequent years. The same impact was assumed after hip and clinical vertebral fractures. We conservatively assumed that only $25 \%$ of the excess mortality following a hip or vertebral fracture could be directly or indirectly attributable to the fractures themselves. Utility values in the general French population (used for patients without fracture) was estimated at 0.766 [24]. Relative reductions due to fractures in the year following the fracture and in subsequent years were derived from a systematic review [25].

The health care perspective was used for the cost estimation. As productivity losses are limited in patients over 60 years, the perspective is quasi-societal. The cost of hip and wrist fractures was derived from the study of Bouee et al. [26]. The cost of clinical vertebral fracture was derived from a previous cost-effectiveness analysis in France [27]. The cost of other fractures was assumed to represent $17.6 \%$ 
Table 1 Population estimates (2015) and projections for 2025 and 2050 in the general French population aged over 60 years

\begin{tabular}{|c|c|c|c|c|c|c|}
\hline \multirow{2}{*}{$\begin{array}{l}\text { French population } \\
\text { (age in years) }\end{array}$} & \multicolumn{3}{|l|}{ Women } & \multicolumn{3}{|l|}{ Men } \\
\hline & 2015 & 2025 & 2050 & 2015 & 2025 & 2050 \\
\hline $60-69$ & $3,961,492$ & $4,171,501$ & $4,038,239$ & $3,614,450$ & $3,783,468$ & $3,921,701$ \\
\hline $70-79$ & $2,507,933$ & $3,663,128$ & $3,786,400$ & $2,036,842$ & $3,045,407$ & $3,321,749$ \\
\hline$\geq 80$ & $2,458,810$ & $2,679,558$ & $4,832,570$ & $1,324,216$ & $1,525,294$ & $3,109,529$ \\
\hline
\end{tabular}

from the cost of hip fracture, in line with Melton et al. [28]. All costs were expressed in $€ 2015$ using the national price index (health index) and a discount rate of $3 \%$ was used for both costs and outcomes. The costs of fractures for the year 2015 were thus estimated at $€ 11,970, € 6201, € 2124$, and $€ 2093$ for hip, clinical vertebral, wrist, and other fractures, respectively. Hip fractures are also associated with long-term costs. These long-term costs were based on the proportion of patients being institutionalized after the fracture. Based on the study of Drame et al. [29], 20.1\% of patients with a hip fracture were institutionalized after a hip fracture in French population aged above 75 years. For patients aged between 60 and 74 years, we conservatively assumed that $10 \%$ of patients were institutionalized after a hip fracture in line with international studies [1]. The yearly costs of nursing home were estimated at $€ 37,255$ based on national data.

The effect of adequate intake of calcium and vitamin D was derived from a recent Cochrane Review [30]. Based on this review, the fracture incidence reduction of vitamin D and calcium intervention was $16,14,11$, and $11 \%$ for hip fracture, clinical vertebral, wrist, and other fractures, respectively. These estimations are slightly more conservative that those used in previous economic evaluations of calcium and vitamin D $[14,17]$ (estimated at $18,13,20$, and $20 \%$, respectively). In the model, people only received fortified dairy products for 1 year (2015 in base case), and no further effect was assumed after the year of treatment. The model has however a lifetime horizon to capture the long-term benefits of preventing fractures in the year of the intake of fortified dairy products.

The cost of one vitamin D-fortified dairy product was estimated at $€ 0.27$ in France based on the prices of two leading industry suppliers from three French cities for vitamin Denriched milk and yogurt (on the date of 20/01/2016). Based on current consumption of calcium and vitamin D in France and European recommendation on adequate levels [3, 6], two vitamin $\mathrm{D}$ fortified dairy products per day are needed to achieve optimal intake of calcium and vitamin $\mathrm{D}$. We therefore assumed the price of two dairy products per day in the base case for the economic analysis.

\section{Presentation of results and sensitivity analyses}

We estimated the lifetime number of fractures prevented (per type), life years gained, and QALY gained of recommended dairy intake versus absence of appropriate intake for the year 2015. Data are presented for the overall population aged over 60 years as well as per age group and gender. Incremental cost-effective ratios (ICERs) were estimated for the recommended intake of fortified dairy products versus usual care. ICERs are defined as the differences in costs between alternatives divided by their differences in outcomes (expressed in QALYs). An ICER represents therefore, the cost per QALY gained of recommended intake of fortified dairy products versus usual care. Projections for the years 2025 and 2050 were also conducted to evaluate the effects of demographic changes on the potential benefits of the strategy.

We conducted 11 additional one-way sensitivity analyses (SA) to assess the impact of parameters on the lifetime number of fractures prevented and QALY gained, and on the cost per QALY gained of the recommended dairy intake. SA1: all fracture risk + $25 \%$; SA2: all fracture risk $-25 \%$; SA3: therapy efficacy $+25 \%$; SA 4: therapy efficacy $-25 \%$; SA5: therapy cost $+50 \%$ (three dairy products per day); SA6: therapy cost $-50 \%$ (one dairy product per day); SA7: $80 \%$ intake of dairy products based on current levels of calcium and vitamin D intake in France [8]; SA8: $50 \%$ intake of dairy products; SA9: therapy cost for all patients but benefits for $75 \%$; SA10: no increased fracture risk after previous fractures; SA11: an
Table 2 Fracture incidence in the general French population aged over 60 years

\begin{tabular}{|c|c|c|c|c|c|c|c|c|}
\hline \multirow{2}{*}{$\begin{array}{l}\text { Fracture incidence } \\
\text { (per 1000) (age in years) }\end{array}$} & \multicolumn{4}{|c|}{ Women } & \multicolumn{4}{|l|}{ Men } \\
\hline & Hip & $\mathrm{CV}$ & Wrist & Others & Hip & $\mathrm{CV}$ & Wrist & Others \\
\hline $60-74$ & 0.117 & 0.181 & 0.313 & 0.394 & 0.074 & 0.135 & 0.100 & 0.528 \\
\hline $75-84$ & 0.689 & 0.551 & 0.551 & 1.311 & 0.323 & 0.298 & 0.077 & 0.861 \\
\hline$\geq 85$ & 2.312 & 1.087 & 0.986 & 3.884 & 1.255 & 0.842 & 0.230 & 3.682 \\
\hline
\end{tabular}

$C V$ clinical vertebral 
Table 3 Projected health impact of vitamin D-fortified dairy products in the general population aged over 60 years in France in the year 2015

\begin{tabular}{|c|c|c|c|c|c|c|c|c|}
\hline & \multicolumn{4}{|c|}{ Women } & \multicolumn{4}{|l|}{ Men } \\
\hline & $\begin{array}{l}60- \\
69\end{array}$ & $70-79$ & $80+$ & $\begin{array}{l}\text { All } \\
(\geq 60 \text { years })\end{array}$ & $\begin{array}{l}60- \\
69\end{array}$ & $\begin{array}{l}70- \\
79\end{array}$ & $80+$ & $\begin{array}{l}\text { All } \\
\text { ( } \geq 60 \text { years) }\end{array}$ \\
\hline \multicolumn{9}{|c|}{ Lifetime fractures saved } \\
\hline Hip & 844 & 3729 & 10,514 & 15,087 & 437 & 1198 & 2778 & 4413 \\
\hline $\mathrm{CV}$ & 1169 & 2087 & 4197 & 7452 & 846 & 851 & 1326 & 3023 \\
\hline Wrist & 1490 & 1959 & 2646 & 6094 & 351 & 196 & 491 & 1037 \\
\hline Other & 2199 & 4284 & 11,357 & 17,839 & 2440 & 2047 & 5499 & 9986 \\
\hline Total & 5701 & 12,058 & 28,714 & 46,472 & 4073 & 4292 & 10,094 & 18,460 \\
\hline QALY gained & 4474 & 6919 & 11,674 & 23,067 & 2958 & 2795 & 3748 & 9502 \\
\hline $\begin{array}{c}\text { Life years } \\
\text { gained }\end{array}$ & 4946 & 5177 & 9256 & 19,378 & 3889 & 2693 & 3209 & 9791 \\
\hline
\end{tabular}

$C V$ clinical vertebral, $Q A L Y$ quality-adjusted life years, $Y$ years additional $8 \%$ costs for marketing and education costs to raise consumer awareness and ensure their acceptance, based on a German study estimate [15]. Results of the sensitivity analyses are presented in tornado diagrams.

\section{Results}

Table 3 summarizes the projected health impact of the recommended intake of fortified dairy products compared to the absence of appropriate intake for women and men aged over 60 years in 2015 in France. The total lifetime number of fractures was reduced by 64,932 for the recommended intake of dairy products in the general population over 65 years, of which 46,473 and 18,460 occurred in women and men, respectively. In particular, 15,087 and 4413 hip fractures could be prevented in women and men. The intake of dairy products resulted in a QALY gained of 32,569 and a gain of 29,169 life years. Most of the benefits of fortified dairy products occurred in women and men aged over 80 years, respectively, 62 and $55 \%$ of fractures prevented can be found in these populations. Results of the sensitivity analysis assuming an adherence level of $82 \%$ can be found in online supplement.

In Table 4, projections of the health impact of fortified dairy products for the years 2025 and 2050 are presented. Taken into account demographic changes only, we estimated that 19 and $78 \%$ more fractures could be prevented with appropriate intake of fortified dairy products in the years 2025 and 2050, respectively.

The total cost impact of the two extra vitamin D fortified dairy products/day compared with usual intake was estimated for the year 2015 at $€ 1555$ million in the general population aged over 60 years. The cost of dairy products was estimated at $€ 2570$ million and $€ 1014$ million were saved because of less fractures resulting from intervention efficacy. Overall,
$39 \%$ of the cost of dairy products would then be compensated by saved costs resulting from fewer fractures.

The incremental cost-effectiveness ratio (expressed in cost per QALY gained) of appropriate intake of fortified dairy products compared with the absence of appropriate intake is reported in Table 5. The ICER is estimated at $€ 58,244$ per QALY gained in the French population aged over 60 years. The ICER was $€ 38,526$ and $€ 106,113$ in women and men, respectively. The ICER was below the threshold of $€ 30,000$ per QALY gained in women aged above 70 years and in men aged over 80 years. Projections of cost-effectiveness suggest that the ICER in the general population aged above 60 years would decrease to $€ 55,953$ in the year 2025 and to $€ 43,620$ in 2050. Sensitivity analyses assuming the cost of one and three dairy products per day are also included in Table 5. One fortified dairy product per day is highly cost-effective in the French general population aged above 60 years (ICER of $€ 10,121$ per QALY gained).

Table 4 Projection of health impact of dairy products in the general population aged over 60 years in France for the years 2025 and 2050

\begin{tabular}{|c|c|c|c|c|c|}
\hline \multicolumn{3}{|c|}{ Women } & \multicolumn{3}{|l|}{ Men } \\
\hline 2015 & 2025 & 2050 & 2015 & 2025 & 2050 \\
\hline
\end{tabular}

Lifetime fractures prevented

\begin{tabular}{lrrrrrr} 
Hip & 15,087 & 17,793 & 27,155 & 4413 & 5449 & 8952 \\
CV & 7452 & 8852 & 12,591 & 3023 & 3685 & 5419 \\
Wrist & 6094 & 7313 & 9675 & 1037 & 1225 & 1853 \\
Other & 17,839 & 20,949 & 31,030 & 9986 & 11,949 & 18,899 \\
Total & 46,472 & 54,907 & 80,451 & 18,460 & 22,308 & 35,123 \\
QALY gained & 23,067 & 27,539 & 37,951 & 9502 & 11,594 & 16,570 \\
Life years gained & 19,378 & 22,856 & 31,049 & 9791 & 11,794 & 16,146 \\
\hline
\end{tabular}

$C V$ clinical vertebral, $Q A L Y$ quality-adjusted life years 
Table 5 Cost-effectiveness (expressed in cost per QALY gained) of the recommended intake of vitamin D-fortified dairy products compared to usual care in the French general population aged over 60 years

\begin{tabular}{clll}
\hline Population & One dairy product per day & Two dairy products per day & Three dairy products per day \\
\hline Overall & $€ 10,121$ & $€ 58,244$ & $€ 106,367$ \\
Women & & & \\
$60-69$ & $€ 67,640$ & $€ 155,006$ & $€ 242,272$ \\
$70-79$ & Cost-saving & $€ 24,997$ & $€ 60,719$ \\
$80+$ & Cost-saving & $€ 1907$ & $€ 22,663$ \\
All ages & $€ 382$ & $€ 38,526$ & $€ 76,670$ \\
Men & & & $€ 338,581$ \\
$60-69$ & $€ 97,772$ & $€ 218,176$ & $€ 164,484$ \\
$70-79$ & $€ 20,868$ & $€ 92,676$ & $€ 62,501$ \\
$80+$ & Cost-saving & $€ 27,683$ & $€ 178,460$ \\
All ages & $€ 33,766$ & $€ 106,113$ & \\
Projections (overall) & $€ 103,470$ \\
2025 & $€ 8436$ & $€ 55,953$ & $€ 85,212$ \\
2050 & $€ 2028$ & $€ 43,620$ & \\
\hline
\end{tabular}

${ }^{\text {a }}$ Cost-saving means that intervention costs are lower than saved costs resulting from less fractures
One-way sensitivity analyses are included as tornado diagrams in Fig. 1. The largest change in terms of public health impact (number of fractures prevented or QALYs gained) occurred when reducing dairy products intake (to $50 \%$ ) followed by decreasing therapy efficacy or all fracture risk by $25 \%$ (Fig. 1a, b). The cost-effectiveness of the recommended dairy intake is strongly influenced by the cost of fortified dairy products, the effectiveness of calcium and vitamin $\mathrm{D}$, and the fracture risk of the population.

\section{Discussion}

Our study suggests that an adequate intake of calcium and vitamin $\mathrm{D}$ by the administration of vitamin D fortified dairy products could substantially reduce the burden of osteoporotic fractures in France. We estimated that the recommended intake of fortified dairy products in the year 2015 would lead to a lifetime decrease of 64,932 fractures including 19,500 hip fractures. Given 65,697 hip fractures occurred in the year 2013 in France [2], the benefit of fortified dairy products is therefore substantial. Projections suggest that the number of prevented fractures through appropriate intake of dairy products could even increase by $78 \%$ in the year 2050 taken into account demographic changes.

In addition, we estimated the cost-effectiveness of the recommended intake of vitamin D-fortified dairy products compared to the absence of dietary intake. To draw a conclusion about the cost-effectiveness, the cost per QALY gained has to be compared with a cost-effectiveness threshold. This threshold represents the maximum amount that the decision makers are willing to pay. In France, as in most countries, there is no consensus on cost-effectiveness. In the overall French population aged 60 years and over, we found a cost per QALY gained of $€ 58,244$, in the range of commonly accepted threshold for cost-effectiveness. The intake of fortified dairy products becomes highly cost-effective (cost per QALY $<€ 30,000$ ) in women over 70 years and in men over 80 years.

Similarly, Ethgen et al. also showed that the intake of dairy products is cost-effective in the general population over 70 years in Belgium [31]. Our study is more conservative as we did not incorporate any treatment effect after the year of the intake of fortified dairy products. A large public health benefit expressed in life years and fractures prevented, was also estimated in another Belgian study [14]. However, a different approach was used to assess the public health burden making comparison with our study difficult. In a recent German study, Sandman et al. [15] suggested that the implementation of dietary vitamin $\mathrm{D}$ and calcium food-fortification program in the German population aged 65 years and older would even lead to annual net cost savings. Lower cost for dietary products was used in this study which could explain the more positive benefit of the intervention.

Our study therefore suggests that an adequate intake of calcium and vitamin D by the administration of vitamin Dfortified dairy products could lead to a substantial decrease in the burden of osteoporotic fractures and could be justified from an economic perspective in women over 70 years and in men over 80 years (assuming a threshold of $€ 30,000$ per QALY gained). Decision makers should be aware of the benefits of calcium and vitamin D and could be interested to implement programs to increase the intake of dairy products. Such programs have already been implemented in some countries $[32,33]$. Clinicians should also take actions to improve the consumption of fortified dairy products by their patients.

There are some potential limitations to our study. First, our study was limited to the potential benefits of calcium and vitamin $\mathrm{D}$ on fracture prevention and we could have 
Fig. 1 Tornado diagrams for oneway sensitivity analyses on the health impact expressed in lifetime number of fractures prevented (Fig. 1a), in QALYs gained (Fig. 1b), and on the costeffectiveness (expressed in cost per QALY gained) of vitamin Dfortified dairy products (Fig. 1c) in the general population aged over 60 years in France in the year 2015. SA5, SA6, and SA11 have no impact on the lifetime number of fractures prevented

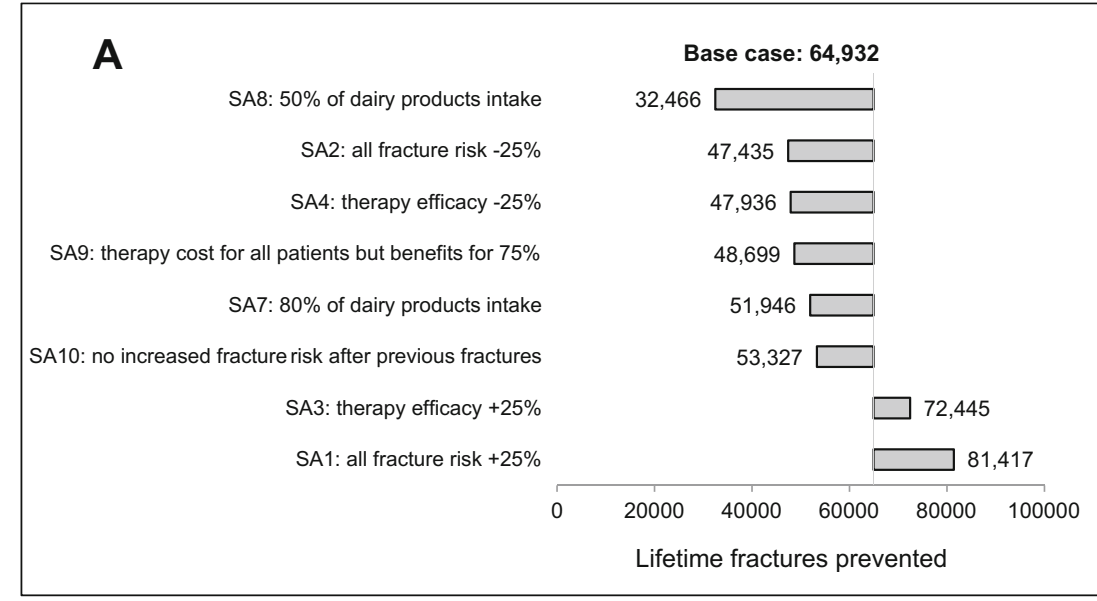

SA5, SA6 and SA11 have no impact on the lifetime number of fractures prevented

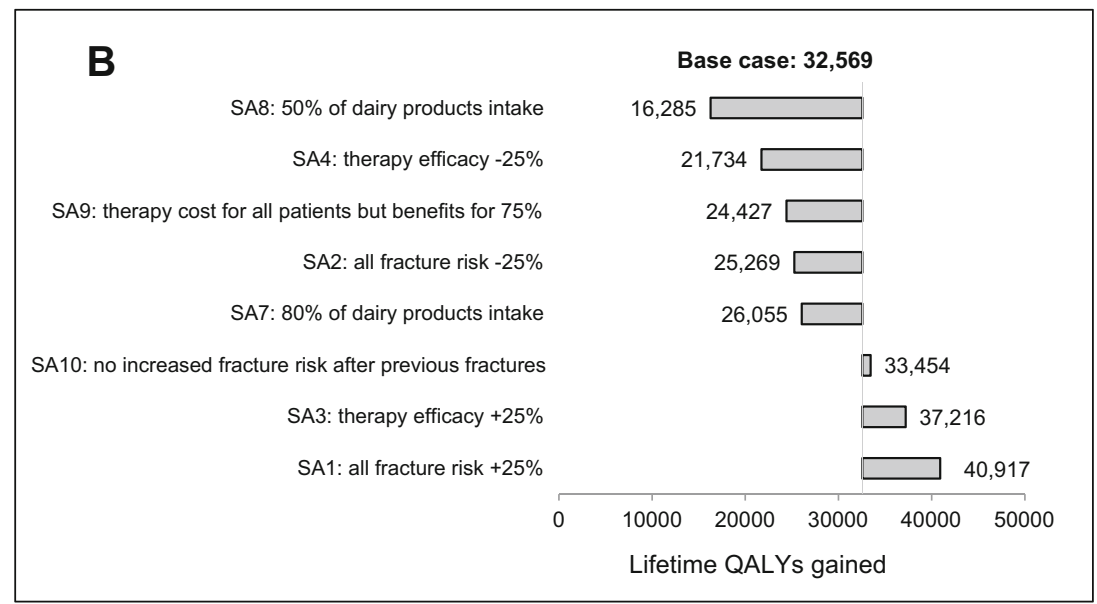

SA5, SA6 and SA11 have no impact on the lifetime QALYs gained

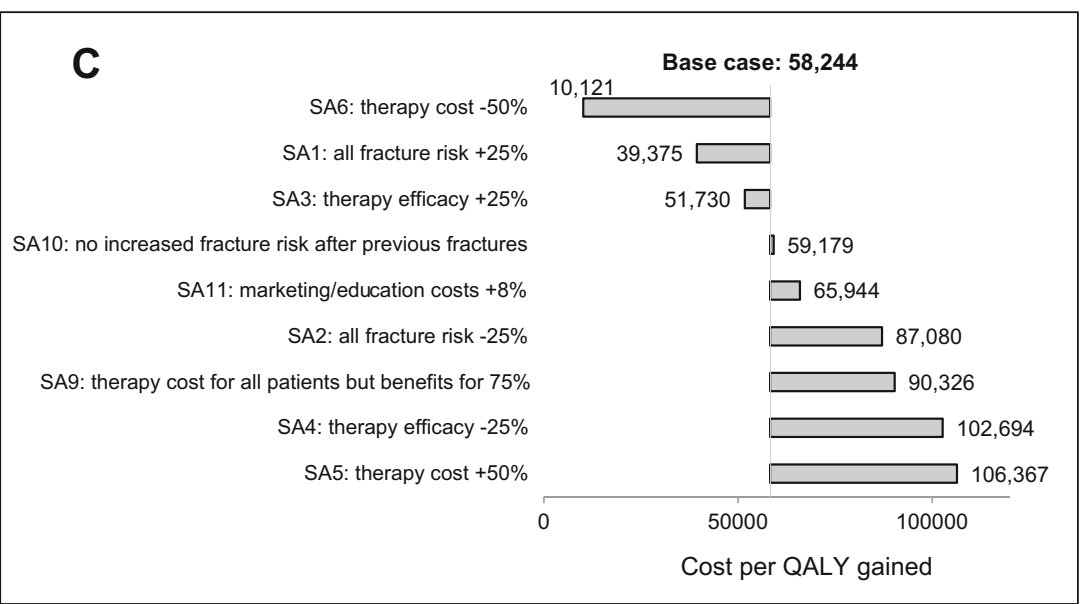

SA7 and SA8 have no impact on the cost per QALYs gained underestimated the benefits of the intervention. There are other potential benefits of calcium and vitamin $\mathrm{D}$ including the reduction on the risk for breast cancer in premenopausal women and colon cancer in older women [34]. Dairy products are 
also rich in proteins which could also lead to extra health benefits [35]. A meta-analysis also indicated that vitamin D may have a small beneficial effect on cardiovascular risk and mortality [36]. On the other hand, we did not incorporate any adverse events although the risk seems limited [37]. Second, a few patients already have an adequate level of calcium and vitamin D through nutrients $[5,6]$. On the opposite, the benefits for some patients with large insufficiency in vitamin $\mathrm{D}$ and/or calcium could be even larger than the assumed effect. Having an adequate level of calcium and vitamin D could also lead to higher benefits of pharmacological treatment for osteoporosis [14]. We could reasonably assume that all these effects could compensate each other. Third, we did not specifically incorporate adherence to fortified dairy products in the analysis. Little is known about adherence to fortified dairy products and how this could affect intervention efficacy. In sensitivity analyses, we assumed that only 80 or $50 \%$ of patients would be willing to consume fortified dairy products. Further studies are needed to assess adherence to fortified dairy products and willingness of the French population to consume fortified dairy products. Lastly, the effect of calcium and vitamin D on fracture risk reduction was derived from a Cochrane Review that was based on all trials about calcium and vitamin D compounds [30]. Further studies are needed to assess the effects of calcium and vitamin D by the administration of fortified dairy products.

In conclusion, this study suggests that the intake of vitamin D fortified dairy products have the potential to substantially reduce the burden of osteoporotic fractures and could be an economically beneficial strategy in France, especially in the general population aged above 70 years.

\begin{abstract}
Acknowledgments The Department of Public Health, Epidemiology and Health Economics of the University of Liege has received an unrestricted educational grant from CNIEL (Paris, France). The funding agreement ensured the authors' independence in designing the study, interpreting the data, and writing and publishing the report. We thank the Prince Mutaib Bin Abdullah Chair for Biomarkers of Osteoporosis and Deanship of Scientific Research, King Saud University for their support.
\end{abstract}

\section{Compliance with ethical standards}

Conflicts of interest Jean-Yves Reginster has received research grant and/or consulting fees from Servier, Novartis, Negma, Lilly, Wyeth, Amgen, GlaxoSmithKline, Roche, Merckle, Nycomed-Takeda, NPS, IBSA Genevrier, Theramex, UCB, Asahi Kasei, Endocyte, Merck Sharp and Dohme, Rottapharm, Teijin, Teva, Analis, NovoNordisk, Ebewee Pharma, Zodiac, Danone, Will Pharma, Meda, Bristol Myers Squibb, Pfizer, Organon, Therabel, Boehringer, Chiltern, Galapagos. Patrice Fardellone has received consulting fees from the following: Amgen, Candia, Danone, Expanscience, Lilly, Roche-Chugaï, Pfizer, and UCB. Mickael Hiligsmann, Nansa Burlet, and Nasser Al-Daghri have no relevant competing interests to declare.
Open Access This article is distributed under the terms of the Creative Commons Attribution-NonCommercial 4.0 International License (http:// creativecommons.org/licenses/by-nc/4.0/), which permits any noncommercial use, distribution, and reproduction in any medium, provided you give appropriate credit to the original author(s) and the source, provide a link to the Creative Commons license, and indicate if changes were made.

\section{References}

1. Svedbom A, Hernlund E, Ivergard M, Compston J, Cooper C, Stenmark J, McCloskey EV, Jonsson B, Kanis JA (2013) Osteoporosis in the European Union: a compendium of countryspecific reports. Arch Osteoporos 8:137. doi:10.1007/s11657-0130137-0

2. Briot K, Maravic M, Roux C (2015) Changes in number and incidence of hip fractures over 12 years in France. Bone 81:131-137. doi:10.1016/j.bone.2015.07.009

3. Rizzoli R, Boonen S, Brandi ML, Bruyere O, Cooper C, Kanis JA, Kaufman JM, Ringe JD, Weryha G, Reginster JY (2013) Vitamin D supplementation in elderly or postmenopausal women: a 2013 update of the 2008 recommendations from the European Society for Clinical and Economic Aspects of Osteoporosis and Osteoarthritis (ESCEO. Curr Med Res Opin 29(4):305-313. doi:10.1185 /03007995.2013.766162

4. Bruyere O, De Cock C, Mottet C, Neuprez A, Malaise O, Reginster JY (2009) Low dietary calcium in European postmenopausal osteoporotic women. Public Health Nutr 12(1):111-114. doi:10.1017 /S1368980008002024

5. Bruyere O, Slomian J, Beaudart C, Buckinx F, Cavalier E, Gillain S, Petermans J, Reginster JY (2014) Prevalence of vitamin D inadequacy in European women aged over 80 years. Arch Gerontol Geriatr 59(1):78-82. doi:10.1016/j.archger.2014.03.010

6. Fardellone P, Cotte FE, Roux C, Lespessailles E, Mercier F, Gaudin $\mathrm{AF}$ (2010) Calcium intake and the risk of osteoporosis and fractures in French women. Joint, bone, spine : revue du rhumatisme 77(2): 154-158. doi:10.1016/j.jbspin.2009.08.007

7. De Cock C, Bruyere O, Collette J, Reginster JY (2008) Vitamin D inadequacy in French osteoporotic and osteopenic women. Joint, bone, spine : revue du rhumatisme 75(5):567-572. doi:10.1016/j. jbspin.2007.10.012

8. Dupuy C, Lauwers-Cances V, van Kan GA, Gillette S, Schott AM, Beauchet O, Annweiler C, Vellas B, Rolland Y (2013) Dietary vitamin $\mathrm{D}$ intake and muscle mass in older women: results from a cross-sectional analysis of the EPIDOS study. J Nutr Health Aging 17(2):119-124. doi:10.1007/s12603-012-0089-x

9. Czernichow S, Fan T, Nocea G, Sen SS (2010) Calcium and vitamin D intake by postmenopausal women with osteoporosis in France. Curr Med Res Opin 26(7):1667-1674. doi:10.1185 /03007995.2010.483658

10. Mensink GB, Fletcher R, Gurinovic M, Huybrechts I, Lafay L, Serra-Majem L, Szponar L, Tetens I, Verkaik-Kloosterman J, Baka A, Stephen AM (2013) Mapping low intake of micronutrients across Europe. Br J Nutr 110(4):755-773. doi:10.1017 /S000711451200565X

11. Rizzoli R, Boonen S, Brandi ML, Burlet N, Delmas P, Reginster JY (2008) The role of calcium and vitamin $D$ in the management of osteoporosis. Bone 42(2):246-249. doi:10.1016/j. bone.2007.10.005 
12. Kanis JA, McCloskey EV, Johansson H, Cooper C, Rizzoli R, Reginster JY, Scientific Advisory Board of the European Society for C, Economic Aspects of O, Osteoarthritis, the Committee of Scientific Advisors of the International Osteoporosis F (2013) European guidance for the diagnosis and management of osteoporosis in postmenopausal women. Osteoporos Int 24(1):23-57. doi:10.1007/s00198-012-2074-y

13. French National Nutrition and Health Program. 2015. Available from http://social-sante.gouv.fr/IMG/pdf/PNNS_UK_INDD_V2. pdf.

14. Ethgen O, Hiligsmann M, Burlet N, Reginster JY (2015) Public health impact and cost-effectiveness of dairy products supplemented with vitamin $\mathrm{D}$ in prevention of osteoporotic fractures. Arch Public Health 73:48. doi:10.1186/s13690-015-0099-3

15. Sandmann A, Amling M, Barvencik F, Konig HH, Bleibler F (2015) Economic evaluation of vitamin D and calcium food fortification for fracture prevention in Germany. Public Health Nutr:110. doi:10.1017/S1368980015003171

16. Lotters FJ, Lenoir-Wijnkoop I, Fardellone P, Rizzoli R, Rocher E, Poley MJ (2013) Dairy foods and osteoporosis: an example of assessing the health-economic impact of food products. Osteoporos Int 24(1):139-150. doi:10.1007/s00198-012-1998-6

17. Hiligsmann M, Ben Sedrine W, Bruyere O, Evers SM, Rabenda V, Reginster JY (2015) Cost-effectiveness of vitamin D and calcium supplementation in the treatment of elderly women and men with osteoporosis. Eur J Pub Health 25(1):20-25. doi:10.1093 /eurpub/cku119

18. Hiligsmann M, Ethgen O, Bruyere O, Richy F, Gathon HJ, Reginster JY (2009) Development and validation of a Markov microsimulation model for the economic evaluation of treatments in osteoporosis. Value Health 12(5):687-696. doi:10.1111/j.15244733.2008.00497.x

19. Hiligsmann M, Reginster JY (2011) Cost effectiveness of denosumab compared with oral bisphosphonates in the treatment of post-menopausal osteoporotic women in Belgium. PharmacoEconomics 29(10):895-911. doi:10.2165/11539980000000000-00000

20. INSEE, Estimations de population au 1er janvier 2015 en France métropolitaine (données provisoires arrêtées à fin 2014).

21. INSEE, Projections de population 2007-2060 en France Métropolitaine.

22. INSEE, Statistiques de l'état civil et estimations de population. Table de mortalité des années 2011-2013, données provisoires arrêtées à fin décembre 2014. N 167 Société - avril 2015.

23. Haentjens P, Magaziner J, Colon-Emeric CS, Vanderschueren D, Milisen K, Velkeniers B, Boonen S (2010) Meta-analysis: excess mortality after hip fracture among older women and men. Ann Intern Med 152(6):380-390. doi:10.7326/0003-4819-152-6201003160-00008

24. Prigent A, Auraaen A, Kamendje-Tchokobou B, Durand-Zaleski I, Chevreul K (2014) Health-related quality of life and utility scores in people with mental disorders: a comparison with the non-mentally ill general population. Int J Environ Res Public Health 11(3):28042817. doi:10.3390/ijerph110302804
25. Hiligsmann M, Ethgen O, Richy F, Reginster JY (2008) Utility values associated with osteoporotic fracture: a systematic review of the literature. Calcif Tissue Int 82(4):288-292. doi:10.1007 /s00223-008-9117-6

26. Bouee S, Lafuma A, Fagnani F, Meunier PJ, Reginster JY (2006) Estimation of direct unit costs associated with non-vertebral osteoporotic fractures in five European countries. Rheumatol Int 26(12): 1063-1072. doi:10.1007/s00296-006-0180-x

27. Cotte FE, De Pouvourville G (2011) Cost of non-persistence with oral bisphosphonates in post-menopausal osteoporosis treatment in France. BMC Health Serv Res 11:151. doi:10.1186/1472-6963-11151

28. Melton LJ 3rd, Thamer M, Ray NF, Chan JK, Chesnut CH 3rd, Einhorn TA, Johnston CC, Raisz LG, Silverman SL, Siris ES (1997) Fractures attributable to osteoporosis: report from the National Osteoporosis Foundation. J Bone Miner Res 12(1):1623. doi:10.1359/jbmr.1997.12.1.16

29. Drame M, Fierobe F, Lang PO, Jolly D, Boyer F, Mahmoudi R, Somme D, Laniece I, Heitz D, Gauvain JB, Voisin T, De Wazieres B, Gonthier R, Ankri J, Saint-Jean O, Couturier P, Jeandel C, Blanchard F, Novella JL (2011) Predictors of institution admission in the year following acute hospitalisation of elderly people. J Nutr Health Aging 15(5):399-403

30. Avenell A, Mak JC, O'Connell D (2014) Vitamin D and vitamin D analogues for preventing fractures in post-menopausal women and older men. Cochrane Database Syst Rev 4:CD000227. doi:10.1002 /14651858.CD000227.pub4

31. Ethgen O, Hiligsmann M, Burlet N, Reginster JY (2016) Cost-effectiveness of personalized supplementation with vitamin D-rich dairy products in the prevention of osteoporotic fractures. Osteoporos Int 27(1):301-308. doi:10.1007 /s00198-015-3319-3

32. Kiely M, Black LJ (2012) Dietary strategies to maintain adequacy of circulating 25-hydroxyvitamin D concentrations. Scandinavian journal of clinical and laboratory investigation Supplementum 243: 14-23. doi:10.3109/00365513.2012.681893

33. Calvo MS, Whiting SJ (2013) Survey of current vitamin D food fortification practices in the United States and Canada. J Steroid Biochem Mol Biol 136:211-213. doi:10.1016/j.jsbmb.2012.09.034

34. Lin J, Manson JE, Lee IM, Cook NR, Buring JE, Zhang SM (2007) Intakes of calcium and vitamin $\mathrm{D}$ and breast cancer risk in women. Arch Intern Med 167(10):1050-1059. doi:10.1001 /archinte.167.10.1050

35. Rizzoli R (2014) Dairy products, yogurts, and bone health. Am J Clin Nutr 99(5 Suppl):1256S-1262S. doi:10.3945 /ajen.113.073056

36. Bjelakovic G, Gluud LL, Nikolova D, Whitfield K, Wetterslev J, Simonetti RG, Bjelakovic M, Gluud C (2014) Vitamin D supplementation for prevention of mortality in adults. Cochrane Database Syst Rev 1:CD007470. doi:10.1002/14651858.CD007470.pub3

37. Holick MF (2015) Vitamin D is not as toxic as was once thought: a historical and an up-to-date perspective. Mayo Clin Proc 90(5): 561-564. doi:10.1016/j.mayocp.2015.03.015 